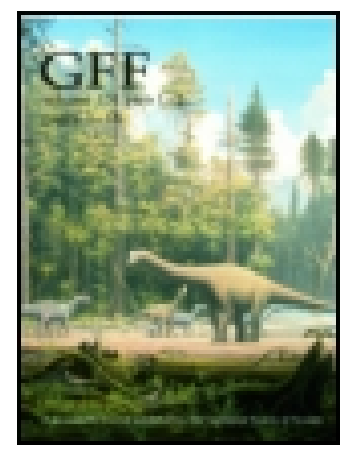

Geologiska Föreningen i Stockholm Förhandlingar

\title{
Slättbergs och Kuso nickelgrufvor
}

\section{G. Löfstrand}

To cite this article: G. Löfstrand (1903) Slättbergs och Kuso nickelgrufvor, Geologiska Föreningen i Stockholm Förhandlingar, 25:2, 103-122, DOI: $10.1080 / 11035890309443451$

To link to this article: http://dx.doi.org/10.1080/11035890309443451

$$
\text { 曲 Published online: } 06 \text { Jan } 2010 .
$$

Submit your article to this journal $\pi$

Џll Article views: 6

Q View related articles $\longleftarrow$

4 Citing articles: 2 View citing articles $\square$ 
GEOน. FöREN. FöRIIANDL. N:o 219. Bd 25. Häft. 2. 103

\section{Slïttbergs och Kúso nickelgrufror.}

Af

G. LöfSTRAND.

Sedan Klefva nickelgrufva år 1888 nedlades p̊̊ den grund, att nickelmalmen derstädes tagit slut, äro Sågmyra nickelverks gamla grufvor Slättberg och Kuso i Dalarne utan tvifvel vårt lands största och mest betydande nickelmalmfyndigheter.

Dessa grufvor upptogos och utmålslades som koppargrufvor år 1805 och bearbetades något på koppar. De synas sedan denna tid ingen gång hafva varit sönade. Tillvaron af nickel $i$ dessa grufvors malm synes hafva varit bekant här tidigare än vid K'lefva, då assessor Johan Gotruieb Gann redan air 1817 erbjüd sig att härifrån leverera munderingsbeslag till Stockholms borgerskaps hästgarde. Srårigheter måtte dock hafra visat sig att ur majmerna utvinna någon nickel, ty någon leverans blef icke af före Gaurs år 1819 inträffiade död. ${ }^{1}$ Först 1850 erhölls på förut hos Kongl. Bergskollegium gjord ansökan rättighet att vid Sågmyra uttaga magnetkisens nickelhalt. Detta skedde till en början förmedelst flera rostningsprocesser samt upprepade koncentrationssmaltningar, hvarigenom man erhöll en kopparnickel med omkring $60 \%$ nickel och $3 \pm-37 \%$ koppar. Af sădan kopparnickel erhölls $i$ medeltal omkring 25 ton om airet.

1 J. O. Carbenerg, Srenska Burgrerhens appkomst och utreckling, s. 206. B. G. BREDRERG Metallurgiska anteckningar, h. VI, s. $1 \overline{\text { j̆. }}$ 
Arbetet under de första 20 åren $^{1}$ synes hafva drifvits i gan. ska liten skala. Den utvunna malmmängden vexlade emellan 1,000 och 2,500 ton per år från Slättbergs och Kusofïlten till. sammans och var vanligen störst från Slättberg. Arbetsstyrkan utgjordes vauligen 25 man och 10 pojkar för båda gruffälten tillsammans saint 25 man för hyttarbetena. Sedan grufvorna på 1870-talet blifvit för en uppgifien köpesumma af $3,000,00$ ) tyska mark försálda till ett tyskt bolag, ändrades metoderna für nickelns utvinnande, så att från och med år 1874 hufvudsak. ligen nickelspeiss sändes frân hyțtan.

Sedan privilegier år 1869 erhållits för Sågmyra Vitriol och Rüdfürgsverk, fullbordades detta af det tyska bolaget med en större svafvelsyrefabrik, hvarefter nickeln ur skürstenen på våta vägen uttogs som nickeloxid. Metoderna vid nickelverket iöllos hemliga. Den största malmbrytuingen egde rum under åren 1875 och 1876, under livilka år respektive 4,500 och nära 5,000 ton från båda gruffälten tillsammans uttogos.

Vid mitt besök i Sågmyra sommaren 1877 drefs ännu nickelverket med full fart, men grufarbetet vid Kuso skulle just nedläggas på grund af nickelns stora prisfall från $21.40 \mathrm{kr}$. pr kilo år 1875 till $6.70 \mathrm{kr}$. ăr 1877. Detta stora prisfall förorsa. kades af underrättelserna om de storartade och rika garnieritnickplmalmfyndigheterna från Nya Kaledonien.

Det tyska bolaget hade sålunda knappt hunnit få alla dyrbara grufve- och hyttebyggnader med boningshus för befäl och manskap fullt färdiga, då allt gruf- och hyttearbete $\mathfrak{i}$ början af

1 J. H. I. VoGt uppgifrer i sin uppsats om s Yerdens Nikkelproduktion, G. F. F. 14: 442, att arbetet rid Sagmyra nickelcerk började ir 1865. Detta ârtal är follständiyt gripet ur luften, sii nycket mer som såräl malmbrytningen som produktionen af kopparnickel under de närmast föregílende åren var större än under de närmast efterföljande. Samma fel upprepas i Teknisk Tidskrift 22 februari 1902 af WaLFrid Petersson.

Enligt Bergmästarerelationerna i Kongl. Kommerskollegii Bergsafdelning började byttverksamheten vid Saggmyra år 18501 med utrinnande of $9,180 \mathrm{~kg}$ nickelspeiss och pågick sedan oafbratet till början af 1850 -talet. Malmens nickelhalt ür i dessa relationer anfecknad till $2 \%$ i genomsnitt för bi̊da gruffälten. 
GEOL. Fọ̈REX. FörhaNdL. N:o 219. Bd 25, Häft. 2. 105 1850-talet totalt upphörde, hvarefter såväl grufvor som byggnader några år senare såldes på offentlig auktion.

Sedan nickelpriset ytterligare fallit och under senare hälften af 1590-talet gått ned till $2.25 \mathrm{kr}$. pr kilo närmast. med anlednidg af konkurremsen emellan Nya Kaledonien och de i slutet af 1880-talet upptäckta Sudburydistriktets rika magnetkis-nickelgrufror i Canada, har det på de sista åren åter börjat stiga och är nu öfver 4 .kronor per kilo.

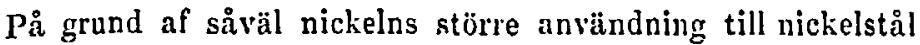
för pansarplåtar och andra militära och civiltekniska ändamål, som ock af nyare metoder för nickelns utvinnande ur magnetkis, livarvid äfven jern $i$ form af $s . k$. sblue bellss. kan ur renare magnethiser med fördel uttagas, hvartill kommer det stigande behofvet af svafvel, torde såväl nickelpriset som värdet af våra nickelförande magnetkisfyndigheter nu vara-och förblifva $i$ stigande.

Med anväudande af MIANHÉs metod, att genom en med bessemerprocessen liknande anordning använda den sista svafvelhalten som bränsle, torde det äfren icke möta stora svårigheter att af nickellaaltig magnethis direkt framställa nickelstål. på grund häraf äro äfven, på senaste tiden såväl ett isoleradt schakt, Rudolfschaktet, det ostligaste vid Slättbergs gruffält, son den största komplexen af Kuso grufror länsade från vatten och något bearbetade. De besöktes af mig $i$ december förlidet år.

Magnethisens, geologiska förekomstsätt vid dessa gruffält har endast blifvit i förbigående omnämnd i den geologiska litteraturen. Endast G. L. WETTERDAuL omnämner något utförligare, att Slättbergmalmen åtföljer en diabasgång och att Kusomalmen förekommer på kontakten enellan diorit och gneis. ${ }^{1}$

Magnetkisens allmänna uppträdande kan $i$ öfrigt uppdelas $i$ tre hufvudgrupper, hvilka hvardera aiter kunna delas i flera underafdelningar. Dessa hufvudgrupper äro:

1) Magnetkis ätföljande vissa basiska eruptivbergarter; nickel kelhalt $1-5 \%$

1 G. I. Wettenduld. Lärobok i grufbrytning, s. 76. 
2) Magnetkis atföljande andra malmer, isynnerhet kopparkis och svafvelkis; nickelhalt omkring $0.1 \%$ $0.5 \%{ }^{1}$

3) Magnetkis uppträdande $i$ falband; nickelhalt 0.1 -

Alla dessa hufvudgrupper af magnetkisförekomster äro företrädda i Sverige.

Till den fürsta gruppen höra alla bearbetade och på nickel tillgodogjorda magnetkisförekomster såväl i Sverige som annorstädes.

Till den andra gruppen hörer den magnetkis, som ätföljer malmerna vid flera af văra större gruffält såsom i Sala, Dannemora och Falun in. ff.

Till den tredje gruppen höra hittills endast föga eller alldeles icke bearbetade, stundom mycket stora tillgångar af magnetkis med mycket stor utsträckning såsom i Grängsbo i Alfta socken af Gefleborgs län, vid Burkürn norr om Ludvika samt å en mycket lång strïcka frăn trakten af Valdemarsvik upp emot Åtvidaberg. Magnetkisen åtföljer härstädes, såvidt jag kunnat finna, alltid omgifvande bergarters såväl strykning soln stupning. Mägtigheten inom samma falband varierar emellan en decimeter och flera meter. Den omgifvande bergarten är antingen gneis, eller skiffirar af dels kvartsitisk dels hornblenderik beskaffenhet och antingen nästan fri från insprängda kiser, eller starkt uppblandad med sădana. Fyndigheten benämnes $\mathrm{i}$ sistnämnda fallet äfven inpregnationszon. Nickelhalten $i$ denna sorts magnetkisfyndighet är ständigt något större, om falbandet förekommer uti hornblende- eller dioritskiffrar, hvaremot magnetkisen är fullkomligt nickelfri, om den såsom vid Grängsbo förekommer i en kvartsitisk skiffer.

1 Jfr J. II. I. Vogr. Zeitschrift für praktische Geologie, 1893. April. 
GEOL. FöREN. FöRHANDL. N:o 219. Bd 25. Häft. 2. 107

\section{Slättbergs grufvor.}

\section{Bergarter.}

Gruffältet, ̊̊ hvars midt Slättbergs jernvägsstation är belägen, sträcker sig $\mathrm{i}$ vestsydrestlig-ostsydostlig riktning och füljer en 2-6 $m$ bred gång af omvandlad diabas, hvaraf stycken synas i varpen vid alla grufvolna. Om denna egendomliga bergart har H. BäcksTrös lemnat följande meddelande:

„Bergarten består öfvervägande af ett ljust blågrönt, aktinolitiskt hornblende, som bildar en filt, i hvilken här och der taflor af titanjern äro inströdda, derjemte finnes mellan hornblendestänglarna litet plagioklas och epidot. Af bergartens primärstruktur torde den enda resten vara de liär och der förekommande strökornen af starkt vittrad plagioklas, hvilka antyda att bergarten varit en basisk porfyrits.

Bergarten har makroskopiskt fullkomligt utseende af en finkornig diabas. Den synes först hafva blifvit sönderdelad i sammanhang med malmens uppträdande, hvilket först synes hafva egt rum, sedan diabasen nagot stelnat. Omvandlingen har äfven varit större, ju bredare malmen varit, att dömma af de hitar jag på gruffältet kunde uppsamla.

$p_{a}$ bottnen af Rudolfs schakt i gruffültets östra ända erbjöd sig vid mitt senaste besök tillfälle att närmare taga kännedom om malmernas och bergarternas närmare förhållanden inbürdes. Se fig. 1 och 2 . Diabasen var $i$ liggande väggen mindre omrandlad ä̀ $i$ hängande väggen och mera omvandlad närmast malmen än längre frăn densamma. Den malmförande gången stupar $85 \%$ mot süder. När omrandlingen fortskridit längst, återstår endast klorit och qvarts af diabasen. Differentieringen kan fortgå så långt, att fullkomligt ren och bryträrd qvarts kan stå att utvinna. Sådan har äfven tillgodogjorts vid Sågmyre nickelverk från schaktet Julius, se fig. 3. Diabasgångens längd är hittills känd till $1,600 m$ och dess bredd variernr emellan 
3 och $6 \mathrm{~m}$; di̊ äfven malmen medräknas. Uppåt Silistria- och Berzeliusgångarna förekomma äfven så rikliga iusprängningar af magnetit uti diabasen, att det från början ifrågasattes att be. arbeta grufrorna på jernmalm.

Fig. 1.
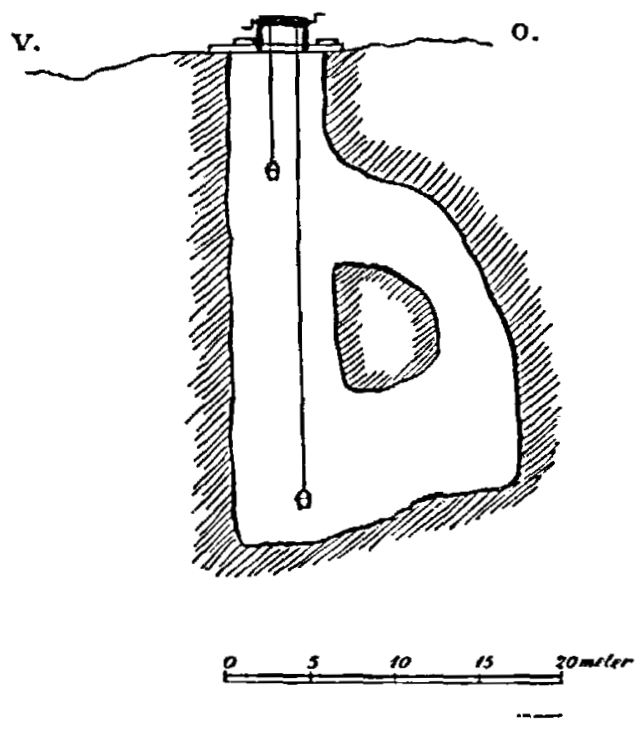

Fig. 2.

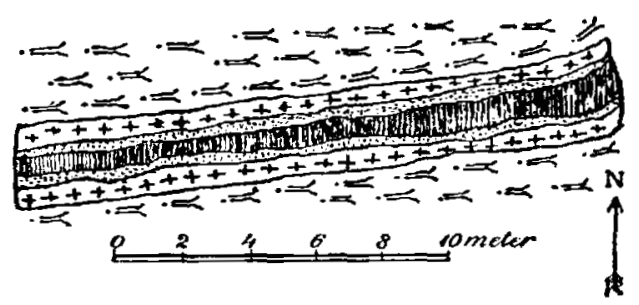

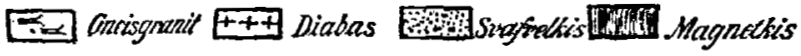

Den rådande bergarten $i$ trakten är en rödlätt, något rresig, lormblendeförande granitisk gneis med mycket otydlig strykning $i$ ungefär samma riktning, VSV-ONO, som den malmförande diabasgingen. Att denna dock är yngre äı den omgifvande 
GEOL. FöREX, FöRHANDL. N:o 219. Bd 25. Häft. 2. 109 bergarten och att hela fyndigheten är en verklig gångspricka, torde vara höjdt öfver allt tvifvel.

\section{Malmerna.}

Magnetkisen har öfver hela Slättbergsfältet fullkomligt samma utseende och såvidt kändt är ungefär samma kemiska sammansättning. Gryet är mycket finkornigt och färgen är icke den vanliga tombacksbruna eller kopparfärgade, utan ljust gulgrå, nästan stålliknande. På de förut omnämnda falbanden kan man ofta fa se mycket kis af detta utseende, men med minst tio gånger mindre nickelhalt. Likheten med den på falband uppträdande magnetkisen är dock så stor, att om icke den malmen åtföljande diabasen stundom vore sii oförändrad till utseendet och upptrïdde $\mathbf{i}$ så stor mängd som nu, skulle hela fyndigheten sannolikt blifvit

Fig. 3.

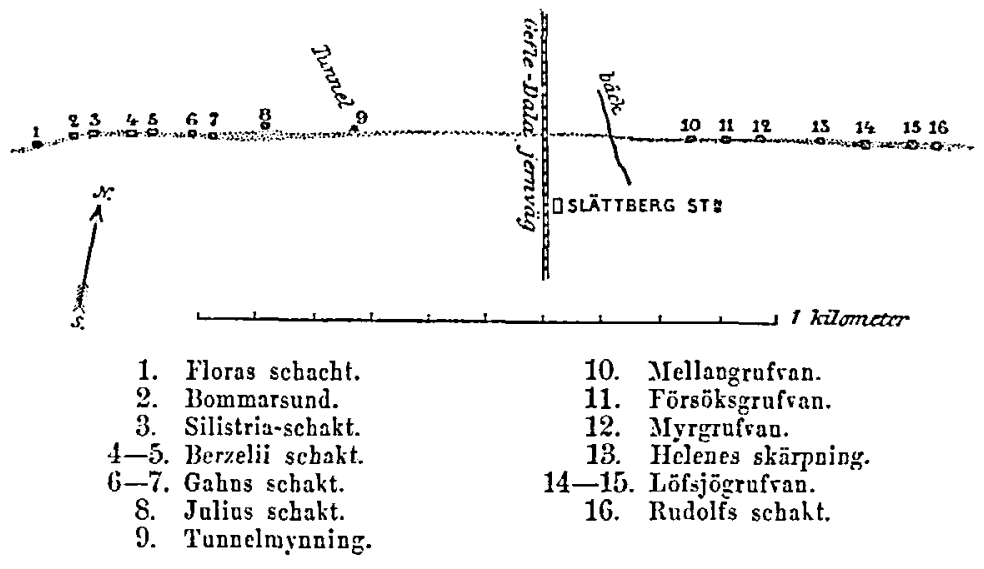

och blifva ansedd som ett falband. Möjligen är icke heller skilnaden så betydande emellan dessa förekomstsätt, i alla händelser icke så stor som emellan Slättbergsfyndigheten och de magnetkisfyndigheter, som uppträda i gabbrodiorit eller gabbro. Hade endast den ătföljande diabasen varit mycket mindre till sin mängd än nu vid Slättberg och de uppträdande kiserna ända 
af samma myckenhet, så hade säkerligen endast qvarts och klorit återstått af diabasen och magnetkisen säkerligen äfven varit mycket nickelfattigare, då $j u$ de basiska eruptivbergarterna anses gifva magnetkisen dess nickelhalt in statu nascendi.

Att magnetkis åtföljer en diabas är för öfrigt ganska säll. synt och torde i Srerige utom vid Slättberg endast förekomma vid Lundörren $\mathrm{i}$ Jemtland. Magnetkisen anses derstädes af $\mathrm{J}$. II. L. VogT ${ }^{1}$ vara en kontaktbildning, men som den under. liggande bergarten utgöres af en kambrisk-silurisk qvarsit, så torde äfven der magnetkisen hafva fảtt $\sin \cdot n$ nickelhalt af 3 till $4 \%$ af den öfrerliggande olivindiabasen. Magnetkisens nickelhalt uppgifves $\mathrm{i}$ officiella handlingar till emellan $1.2 \%$ och $2 \%$ De tvi̊ större generalprof, som jag tagit derstädes vid Myrgrufvan och Rudolfs schakt visade vid af handelskemisten G. PaIJKuLL gjorda analyser:

\begin{tabular}{|c|c|c|}
\hline & Mygrgrufran. & Rodolfs schakt. \\
\hline Jickel i malmen ....... & $1.35 o_{0}^{\prime}$ & $1.31 \%$ \\
\hline Nickel i ren maguetkis ..... & $1.41 \%$ & $1.41 \%$ \\
\hline Srafrel . . . . . . . . . & $37.65 \%$ & $36.79 \%$ \\
\hline Berïknadt jern ........ & $57.00 \%$ & $56.00 \%$ \\
\hline
\end{tabular}

Skilnaden emellan nickelhalten i malmen och den für ren magnetkis berïknade är så obetydlig, att man genast ser, att malmen måste betraktas som nästan helskäft. Ftt pả bottnen af Rudolfs schakt af ett skott taget prof visar enligt en i England utförd analys:

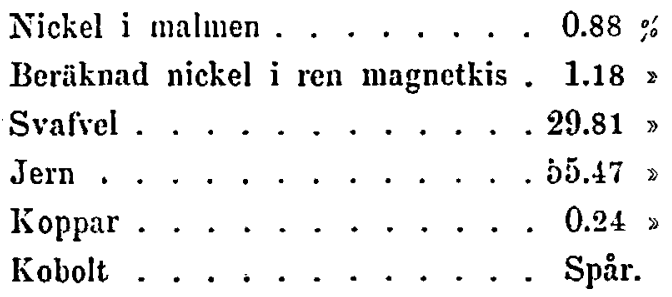

1 J. H. L. Vogr. Malmförekomster i Jemtland och Mrrjedalen. S. G. L. Ser. C. N:o 89. 1887. D. S. Zeitschrift für praktische Geologie. 1S93, Aṇril. 
GEOL. FöREN. FöRIIANDL. N:o 219. Bd 25. Häft. 2. 111

On denna analys är rigtig, lıvilket synes vara åtskilligt trifvel underkastadt, så ingå flera procent jernnalm i magnetkisen. Srafvelhalten motsrarar här endast $51 \%$ jern. Nickell,alten $i$ săväl malmen, som $i$ den efter svafvelhalten beräknade rena magnetkisen är äfven $i$ jemförelse med alla föregående analyser abnormt låg. Att dömma af magnetkisens förut omtalade olika färgnyanser är det dock möjligt, att jernmalmen $i$ form af fint fördelad magnetit stundom ingăr $i$ magnetlisen, l,vilken under sådana omstïndigheter $\mathbf{i}$ sig sjelf blir fattigare på nickel.

Af intresse är, att jernmalm stundom $i$ mycket stor mängd ingăr $i$ den pâ falband uppträdande magnetkisen. Sả kan i trakten af Valdemarsvili vid Karsmåla koppargrufva jernmalmen stundom nästan uttrïnga den med något kopparkis uppblaudade magnetkisen. Jernmalmen ingår derstiides i stora korn och svïfrande kristaller.

Magnetkisens fürekomstsätt vid Slättberg ses bäst af fig. 2, som utvisar magnetkisens förekomstsätt $i$ midten af gången, under det att săräl svafvelkis som diabas på båda sidor ongifvel densamma. Bredden är här knappt en meter, men synes tilltaga mot östra ändan.

I de öfrign grufrorna utom Löfsjögrufrorna, som vid mitt besök voro vattenfyllda, uppgifves malmen icke förekomma midt inuti diabasen săsom vid Rudolfs schakt, utan på södra sidan af densamma emot hängande väggen, endast genom en tunn kloritstöl skild frán granitgneisen.

Malmens bredd uppgifres såäl af arbetare, som deltagit $i$ senaste grufbrytningen, som af fackmän, som besökt grufrorna under denna tid, vara $1.2 \mathrm{~m}$ i vestra grufvefältet cller SilistriaBerzelius-Gahnsgrufvoma samt i mellersta gruffïltet eller Försöks- och Myrgrufroma vexla emellan 2.4 och 2.7 samt ända till $4.5 \mathrm{~m}$.

Den hittills kända, 1,600 $m$ långa malmens medelmägtighet kan derfür icke anses vara för högt tilltagen, om den berïknas till $1.5 \mathrm{~m}$. Att $1,600 \mathrm{~m}$ icke kan vara malmens hela lïngd, visas bäst af' att malmen i östra indan af Rudolfs schakt vidgas samt af 
att den $\mathrm{i}$ restra ändan af Silistria under Floras schakt anstår till oförminskad bredd. Se fig. 3. Den vestra grufkomplexen Flora-Bommarsund-Silistria är sammansprüngd till en längd af $136 m$ och är $45 m$ djup. Strax öster deroın, men icke stående $\mathrm{i}$ sammanhang med de förra, komma Berzelii och Galıns grufvor sammanbrutna till en längd af $90 \mathrm{~m}$ med det pã gruffältet största djupet af omkring $100 \mathrm{~m}$. I grufvan Gahn inkommer på $24 \mathrm{~m}$ djup en stoll af $184 \mathrm{~m}$ längd drifven $\mathrm{i}$ fältrigtningen åt vester. Julius schakt synes vara drifvet såsom sljushål» till denna stoll.

I det utan tvifvel vigtigaste mellersta gruffältet är Mellangrufian. $15 \mathrm{~m}$ djup samt Försōks- och Myrgrufiorna sammanbrutna till en längd af $80 \mathrm{~m}$ med $36 \mathrm{~m}$ djup. Emellan dessa och Löfsjögrufvan finnes midt i myren en jordrymning rakt öfver malmgången, men fast berg synes icke vara uppnådt. Denna jordrymning kallas Helenegrufican.

Löfsjögrufian har tvà dagöppningar nedåt sammanbrutna . på en längd af $75 \mathrm{~m}$. Den vestra gruföppningen är som schakt för vattendunt afsänkt till $66 \mathrm{~m}$. Den öfriga delen af grufkomplexen är endast omkring $26 \mathrm{~m}$ djup. Endast en tunn bergvägg skiljer denna grufkomplex från det $30 \mathrm{~m}$ djupa Rudolfs schaktet, som pả bottnen är afstrossadt emot öster till $17 \mathrm{~m}$ längd. Se fig. 1 .

Under grufarbetena uti dessa langa grufverum uppgifves malmen icke mot năgot håll eller på något ställe hafva utkilat. Icke förty uppoifves malmen $i$ allmïnhet förekomma $i$ linser, hvilket väl endast är att betrakta som skrock från den goda tid, då alla våra malmer med eller emot naturen allmänt betraktades sásom lager. Alla skäl tala deremot för att det hela är en öfver liela fältet sammanhängande malıngång, hvars bästa ställen måhäinda ännu icke äro blottade. Detta är så mycket mera sannolikt, soln kompassen synes hafva blifvit tagen till hijelp vid det senare upptagna östra grufvefältet. Om nu, såsom förut iir omnämndt, magnetisk jermmalm $i$ fint fördeladt tillstånd stundom ingár just $\mathrm{i}$ den $\mathrm{i}$ oclı för sig nickelfattigaste magnetkisen, 
GEOL. FÖREN. FÖRHANDL. N:o 210. Bd 25. Häft. 2. 113 si̊ ger just den sämsta malmen de största magnetiska utslagen.

De olika grufvorna äro dock alla belägna på en så rak linie, att någon svirighet att påträffa malmen på mellanrummen alldeles utan tillhjelp af kompass icke synes föreligga.

Svafielkisens förekomstsätt är endast säkert kändt i Rudolfs schakt. $P a ̊$ varphögarna öfver hela grufältet anträfas dock srafvelkisbitar ganska ymnigt, men inga uppgifter förcligga on dell blifvit anträffad både $i$ hängandet och liggandet såsom $i$ Rudolfs schakt. Deremot omnämnes, att svafvelkis $i$ qvarts blifvit bruten i Julius schakt, som anses vara upptaget i liggande räggen norr om malmgången. Härstädes skulle svafvelkisen sảlunda förekomma $\mathrm{i}$ liggande vägen emellan magnetkisen och den till quarts och klorit omvandlade diabasen.

Svafrelkisen har öfrer hela Slättbergsfältet ett ljust utseende och ett mycket finkornigt gry. Emot längande väggen $i$ Rudolfs schalt var den uppfylld af hålrum och drusrum, lwvilka stundom uppgingo i storlek till verkliga sdrakhåls. De smärre håligheterna voro så talrika, att svafrelkisen till sin struktur stundoin liknade en förstenad tvätsvamp. Denna sorts malm kallas af grufarbetarne för pipmalm.

Som åtskilliga uppgifter förelĭgo, att tyskarne vid Sågmyra under de sista åren grufvorna af dem bearbetades skulle hafva sait högre värde på svafvelkisen än på magnetkisen bland annat på grund af dess större nickelhalt, öfverlemnades af mig tigna generalprof på såräl den täta svafrelkisen i liggandet af $R$ udolfs schakt som af spipmalmen frăn längandet till handelskemisten G. PaIJruld för analyser. Från hängandet är äfven meddelad analys af ett generalprof gjord $i$ England. Resultaten sammanställas i nedanstående tabell.

Under det att svafvelhalten i pipmalmen är nâgot mindre än $i$ den täta svafrelkisen från liggandet, intaga nickel och kobolt ett mycket egendomligt och emot den för dessa metallers förbållande till svafvelkis och magnetkis af J. II. L. VOGT uppställda förträffliga lagen fullkomligt rebelliskt uppträdande. Nickeln 
ingår nämligen $i$ hängande väggens svafvelkis till afsevärdt större mängd än kobolt, under det att nickel- och kobolthalterna i liggande väggens svafvelkis öfverensstämma med den Vogtska lagen, att nickel endast $i$ mycket ringa mängd ingår $i$ svafvel. kisen på en nickelmalmfyndighet, under det att kobolthalten företrïdesvis samlar sig i densamma. IIvarken vid Canadas, Norges eller $i$ văra öfriga nickelgrufvor eger năgot undantag från detta, såvidt jag kunnat. finna af VoGT först pâvisade egendom. liga förhållande rum. Enligt de engelska analyserna är till ock med nickelhalten verkligen stōrre $i$ svafvelkisen $(0.94 \%)$ än $i$ magnetkisen $(0.88 \%)$.

\begin{tabular}{|c|c|c|c|}
\hline 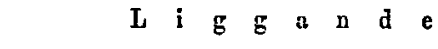 & t. & II $\ddot{\mathrm{a}} \mathrm{n} g$ & a $n d e t$ \\
\hline \multicolumn{2}{|l|}{ Enligt Paijkull. } & $\begin{array}{c}\text { Enl. } \\
\text { PaIJKull. }\end{array}$ & $\begin{array}{c}\text { Fnl. } \\
\text { engelsk analys. }\end{array}$ \\
\hline Srafrel ........... & $45.92:$ & $39.36 \%$ & $42.18 \%$ \\
\hline 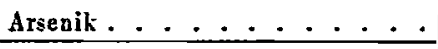 & ringa spår & 一 & - \\
\hline 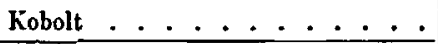 & $0.50 \%$ & $0.12 \%$ & spår \\
\hline Nickel ........... & spir & $0.84 \%$ & $0.94 \%$ \\
\hline 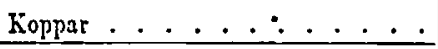 & $0.52 \%$ & $0.26 \%$ & 一 \\
\hline $\operatorname{Jern} \ldots \ldots \ldots$ & 一 & - & $46.35 \%$ \\
\hline
\end{tabular}

Sălunda göra Slättbergs nickelgrufvor äfven i detta afseende undantag från en eljest allmän regel.

Kopparkisen synes i allmänhet förekomma närnast hängande väggen. Sä förekommer den i Rudolfs schalit emellan spipmalmen och diabasen $i$ hängande väggen. I detta afseende synas Slättbergs grufvor öfverensstiimma såväl med Kuso som med våra öfriga nickelgrufvor, att kopparkisen förekommer likasom öfver den öfriga malmen, eller högst uppe emot den angränsande längande vïggen.

\section{Malmängd.}

På grund af allt det omskrifna kan den na kïnda malmens liingd uppskattas till $1,600 \mathrm{~m}$ och dess medelbredd till $1.5 \mathrm{~m}$. 
GEOL. FörEN. FörHANDL. N:o 219. Bd 25. Häft. 2. 115 Detta gifver 10,000 ton malm för hvarje meters afsänkning och sålunda 50,000 ton för som vanligt antagna årsbrytning till $5 \mathrm{~m}$ djup och en million ton efter en afsänkning af $100 \mathrm{~m}$. Som fyndigheten utgöl en verklig sprickgång, pă hvilken malmerna fortsätta till sådana djup, att do aldrig kunna emot djupet utbrytas, kan man med en gräns för grufbrytningsarbetet mot djupet af en kilometer beraikna en totalmängd nickelmalm af tio millioner ton och en tid för denna malmmassas uttagande till tråhundra år.

Enligt mitt förmenande intager äfven Slättbergs nickelgrufvefailt $\mathbf{i}$ afseende $p a ̊$ malmmängden det första rummet icke blott $\mathbf{i}$ Srerige utan i hela Skandinavien. Nickelhalten ïr deremot i stort bearbetade nickelgrufvor bland de lägsta, om ej lägst.

\section{Kuso nickelgrufvor.}

Kuso grufvor inmutades redan 1805 som koppargrufvor. De äro belägna i Aspeboda socken (förut Stora Tuna) samt omkring $4 k m$ emot nordvest från Smedsbo station å den under byggnad varande Vester-Dalarnes jernväg. På 1860-talet utmålslades två sydost om de ganla Kusogrufvorna belïgna Mutto- och Klingsbergsgrnfrorna, si att fyndigheten nu innefattas i tre enligt de äldre grufvestadgarna lagda utmål.

\section{Bergarterna.}

I olikhet med G. L. WETTERDAHL har jag icke kunnat păträffa någon gneis $\mathrm{i}$ närheten af grufrorna, oaktadt en sådan bergart ïr den $i$ trakten rådande, $P a ̊$ denna grund kan jag icke heller finna, att magnetkisen, $i$ likhet med hvad förhållandet är vid de norska nickelförekomsterna, upptrïder på kontakten emellan gabbro och gneis.

Såvidt jag har kunnat finna, upptrïder deremot magnetkisen vid Kuso på kontakten emellan mörk hornblenderik gabbro-

\footnotetext{
1 G. L. WetTERDAIIL. Lärobok i grufbrytning, s. 76.
} 
diorit ̊̊ ena sidan, mot hvilken sida den så småningom blir en. dast en obetydlig impregantion i bergarten, dâ hornblendekristal. lerna samtidigt efter hand aftaga $i$ storlek, och koncentrerar sig deremot $a$ den andra sidan emot ljusa sliror $\mathrm{i}$ bergarten. Ju mera omfattande och stora dessa mera plagioklasrika, ljusa partier äro, desto större äro äfven inalmfallen emot delas kontakt.

Fig. 4.

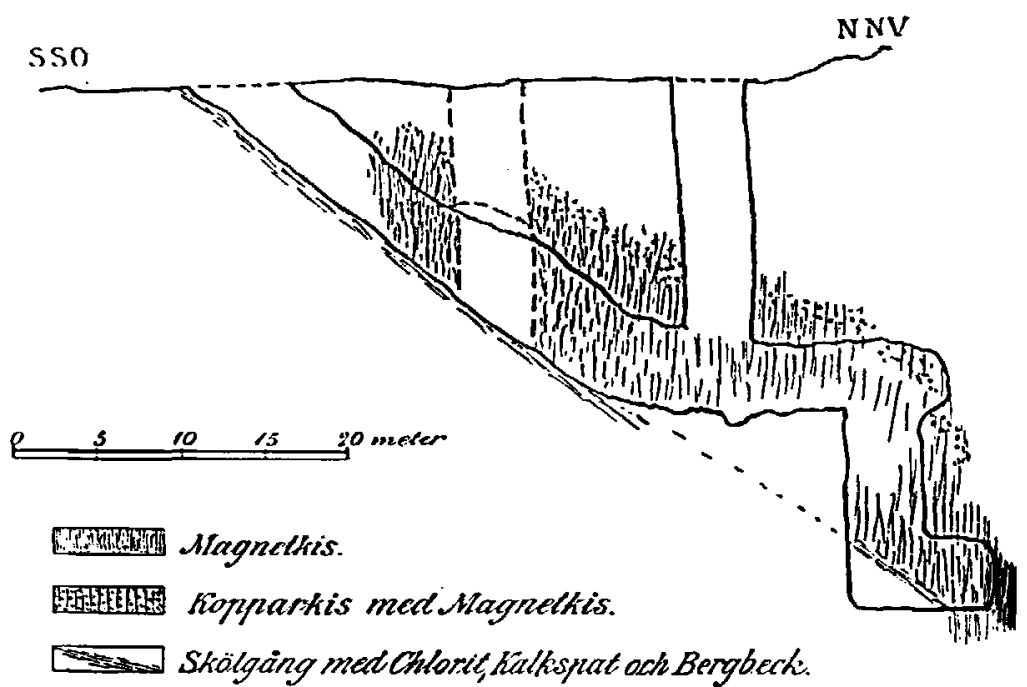

Om sålunda bergarterua och malmens förekomstsätt icke kunna jemföras med de norska nickelfyndigheterna, så är deremot likheten med Klefva nickelmalmfyndighet desto större; till och med sĩ lika, att malm och bergartsstuffer från de båda malmfülten svårligen åtminstone makroskopiskt kunna åtskiljas.

Den ljusa gabbrodioriten utgör vid Kuso grufva hängandet. Fig. 4 utvisar en trärsektion af den största grufvan. Bergarterna vid de nägot mera emot sydost belägna Mfutto- och Illingsbergsgrufvorna äro fullkomligt liknande. 
GEOL. FöREx. FörHANDL. N:o 219. Bd 25. Häft. 2. 117

\section{Malmerna.}

Utom emot den ljusa gabbrodioriten, som troligen har förvexlats med gneis, iir den nickelrikaste malmen samlad efter en slïppa, som följer malmens utsträckning nedåt och utgör gräns för den brytvärda magnetkisen emot liggandeväggen. Se fig. 4. Denua släppa utfylles af klorit, hornblende, rattenklar kalkspat och bergbeck.

Nickelhalten i malmen anses vara störst närmast denna släppa. Efter livad jag kunnat finna, är den dock mera samlad upp emot hängandet, hvarest äfven kopparkis stundom $i$ ganska stor mängd förekommer tillsammans med magnetkisen. Malniens kopparhalt anses $i$ allmänlıet uppgá till $2 \%$ hufvudsakligen på grund af den större inblandningen af kopparkis frain hängandet.

Srafvelkis förekommer äfven, men dess förekomstsütt kunde jag icke utröna vid det enda korta besök, jag gjort i grufvan.

Den rena magnetkisen från hela Kusofältet anses $i$ allmänhet hålla $2.5 \%$ nickel. Emellertid är malmen vanligen så uppblandad med hornblende, att nickelhalten i malmen sällan kan uppgå till detta belopp, utan vanligen endast till hälften.

Några af handelskemisten G. PaIJkULL utförda analyser på af mig tagna generalprof af nickelmalm från Kuso anföras hïr:

\begin{tabular}{|r|r|r|r|r|r|r|r|}
\hline \hline & $\begin{array}{r}1 . \\
\% .\end{array}$ & $\begin{array}{c}2 . \\
\% .\end{array}$ & $\begin{array}{c}3 . \\
\%\end{array}$ & $\begin{array}{c}4 . \\
\%\end{array}$ & $\begin{array}{c}5 . \\
\%\end{array}$ & $\begin{array}{c}6 . \\
\%\end{array}$ & $\begin{array}{c}\text { Eng. } \\
\text { analys. } \\
\% \%\end{array}$ \\
\hline $\begin{array}{r}\text { Nickel i malmen.... } \\
\text { Srafrel . . . . . . }\end{array}$ & $\begin{array}{r}1.82 \\
21.04\end{array}$ & 1.43 & 1.16 & 1.25 & 1.30 & 1.39 & 1.14 \\
$\begin{array}{r}\text { Beräknad nickel i ren mag- } \\
\text { netkis........ }\end{array}$ & 3.42 & 2.90 & 2.52 & 250 & 2.46 & 2.19 & 2.51
\end{tabular}

Prof n:r 2 togs af mig som generalprof på $20 m$ djup $i$ Kuso största grufra vid mitt senaste besök i december förlidet in. 
Prof n:r 3 togs af generalprof, taget af mig på bottnen eller på $32 m$ djup i Kuso största grufva. Den engelska analysen är utförd af samma prof.

Prof 5 och 6 äro utförda pá af mig tagna generalprof af malm $\mathbf{i}$ en liten skärpning, af omkring $3 \mathrm{~m}$ djup invid gamla Kuso grufva.

\section{Jlalmmängd.}

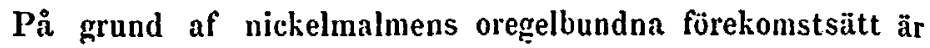
det här ganska vanskligt att nu derom gifva något omdöme, men på grund af Kuso gruffälts stora ussträckning anser jag, att årligen 5,000 ton malm lätt kunna uttagas. Möjligt är äfven, att detta belopp kan fördubblas, men icke heller gärna mera. 'I jemförelse med Slättbergs grufvor skinile man sălunda här hafva en tiondedel intill en femtedel af Slättbergs malmmängd.

IIärvid iir äfren medtaget $\mathrm{i}$ betraktande, att uthålligheten emot djupet hos denna malmtyp icke har visat sig så säker. Săviil vid Klefva som vid Senjens och Meinkjärs nickelgrufvor har malmen enligt VoGT aftagit eller rent af upphört till och med före $100 \mathrm{~m}$ djup.

Af ett sïrskildt intresse är att vi $\mathrm{i}$ rårt land ega en koppargrufra, livarest malmen förekommer på samma sätt som $i$ Kuso n. fl. nickelgrufvor. Detta ür Häradsgrufvan i trakten af Valdemarsvik. Typen är fullkomligt densamma med den skilnaden, att kopparkisen $\mathrm{i}$ hängandeväggen blir den predominerande. I liggandeväggen samt derifrån insprängd $\mathbf{i}$ gabbrodiorit med ymnigt af grofkristalliniskt hornblende förekommer rätt mycket magnetkis. Ur grufvan hafva flera tusen ton kopparkis brutits och nedsmälts i Valdemarsviks kopparverk. Denna malm uppgifves $\mathrm{i}$ allmänhet hafva innehållit $10.30 \%$ koppar och $1.55 \%$ nickel. 
GEOL. Fören. FörhandL. N:o 219. Bd 25. Häft. 2. 119

\section{Ekedals nickelgrufva.}

Ekedals nickelgrufva, belägen vester om vägen emellan Söder och Norra Ekedal inom Enåker socken af Vestmanlands län och onkring $7 \mathrm{~km}$ norr om Runlällens jernvägsstation, äl künd under namn af Carlsgrufvan för öfver hundra år sedan, då den brutits pä kopparmalm.

Under den s. k. gruffebern och det $i$ början af 1870-talet rădande höga nickelpriset återupptogs grufvan af brukspatron $P$. II. Wetterqurst. Med 1,200 dagsverken utvunnos under iren 1870 och 1871 enligt bergmästarerelationerma i Kongl. Kommerskollegii Bergsafdelning 1,030 ton malm, hwilken fördes till Nolnebo bruk, der den förarbetades till nickelskärsten.

Sedan Molnebo bruk öfvergått till utländska egare, nedlades grufdriften såväl i Ekedals nickelgrufva' som i brukets öfriga i orten belïgna grufvor. Malmtillgăngen $i$ grufvan var dock oförändrad och ganska god, uppgående i det nordligaste hörnet af grufvans botten till flera meters bredd.

Grufvans djup uppgår till emellan 10 och $20 \mathrm{~m}$. All uppfordring har skett med handvinseh och på sista tiden med ett tramphjul.

Nickelmalmen eller nagnetkisen är bunden vid gabbrodiorit och förekommer på fullständigt samma sätt som vid Klefva och Kuso nickelgrufvor. Magnetkisen, ätföljd af en obetydlig del svafvelkis och kopparkis, förekommer nämligen anhopad emot ljusare slirformade partier af gabbrodioriten, hvarvid skarp kontakt kan iakttagas emot den ljusa bergarten, under det att en lăngsam 
ofvergang emellan malm- och bergarter eger rum emot den mera hornblenderika och mörka gabbrodioriten.

Sådan ljus gabbrodiorit utan spår af insprängda kiser förekomme: på grufvans östra sida och kan liattast iakttagas i de derstädes företagna försökssprïngningarna, hvilka utgöra tvă mindre skärpningar. Sjelfva grufvan är deremot upptagen på

Fig. 5.

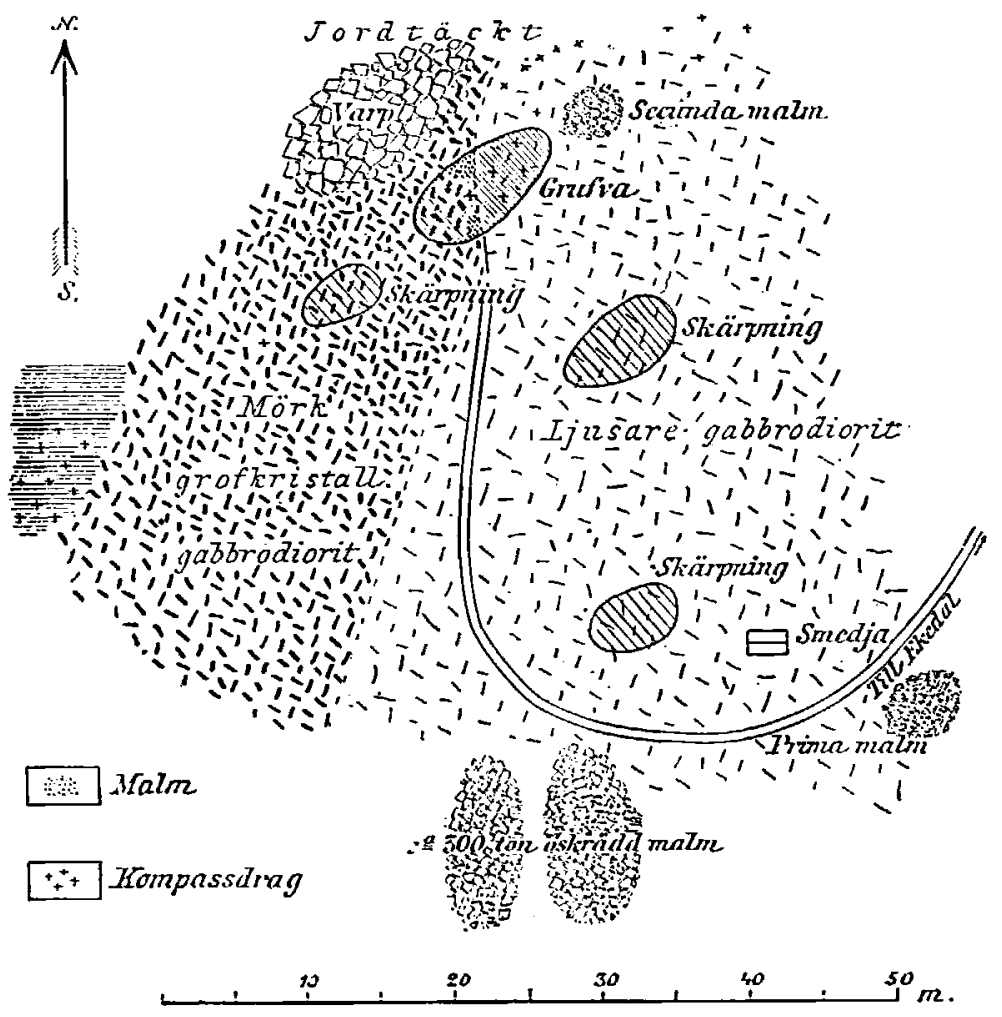

Ekedals nickelgrufua

gränsen emellan dessa båda bergarter. Genom att förmedelst jordmynning noggrannt efterfölja denna gräns kan fyndigheten utan tvifvel erhålla en ganska stor utsträckning. Något arbete i denna riktning synes hitintills icke vara företaget. 
GEOL. Förex. FöritandL. N:o 219. Bd 25. Häft. 2. 121

Då för närvarande ur den ganla grufvan kan brytas minst 1,000 ton malm om året, synes möjligheter sălunda föreligga att genom undersökningsarbeten efter gränsen emellan den ljusa och mörka bergarten flerdubbla detta belopp.

Nickelhalten i magnetkisen synes vara för srenska förhållanden ovanligt hög. Så föreligger en analys af P. M. CarLberg af magnethis i hornblende från Ekedals nickelgrufva med $4.0 \%$ nickel. I medeltal af fyra olika personer utförda analyser fảs $2.68 \%$ nickel.

Nickelhalten synes uppenbart tilltaga $i$ den magnetkis, som förekommer $\mathrm{i}$ den mörkare och mera hornblendehaltiga bergarten.

\section{Gaddbo nickel- och koppargruffält.}

Gaddbo grufvor äro belägna vid Gaddbo gảrd, Simtuna socken af Vestmanlands län. Fyndigheten har en ganska stor utsträckning $i$ ost-restlig riktning. Malmen förekommer som en salbandliknande gång $i$ gabbro, hvilken bergart $i$ sin ordning uppsïtter i kontakten emellan ett gneis- och ett granitområde. Vid mitt besök tillät icke tiden att undersöka mera än den ostliga delen af gruffâltet eller nya inmutningen Björngrufvan, belägen öster om Gaddbo gård, äfven omfattande en gruföppning vester invid gården.

Den grufva, som härstädes hufrudsakligast arbetats pä nickelmalm och är belägen omkring $100 m$ österut från gården, är omkring $6 \mathrm{~m}$ djup samt har en dagöppning af omkring $4 \mathrm{~m}$ i fyrkant. Gabbrobergarten tillstöter på alla sidor, men ïr i södra väggen något. ljusare. Malmen, som har en bredd af omkring $3 m$, synes äfren emot södra sidau vara mera samlad. En sidogren af malmen, năgot öfver en meter bred, inkommer $i$ grufvan från nordvest. Norr derom är gabbrobergarten mörk och grofkornig.

Enligt bergmästarrelationerna i Kongl. Kom. Bergsafd. npptogos under åren 1870 och 1871 med 1,200 dagsverken 1,432 
ton malm, hvaraf en del fördes till Molnebo bruk och smältes till nickelskärsten. Några luundra ton sekunda och oskrädd malm qvarligga ännu vid grufvan. En qvarlemnad skrädd malm. hög norr om grufvan innehöll mycket kopparkis, hvaraf ett taget generalprof vid analyser af två olika personer befanns innehålla öfver 11 procent koppar. God och säljbar kopparkis synes sålunda tydligen kunua utskrädas som värdefull biprodukt vid nic. kelmalmbrytningen.

Nickelhalten i magnetkisen utvisar enligt af två af olika personer gjorda analyser năgot öfver 2 procent. Malmfångsten synes minst kunna uppskattas till 1,500 tou per år, kopparmalmen deruti inberäknad. Iuru. mycket malm, som årligen kan utvinnas från det öfriga gruffältet, kan icke bestämmas. Mlagnetkisens förckomstsätt härstädes synes icke vara närmare studeradt, sedan man fătt de hjelpmedel, som vetenskapen numera derför erbjuder för undersökning af den åtföljande gabbrobergarten. 